To the paper

\title{
ERRATUM
}

\section{Validation of a loss-free counting system for neutron activation analysis with short-lived indicators}

\author{
K. Heydorn, E. Damsgaard
}

Isotope Division, Ris $\phi$ National Laboratory, DK-4000 Roskilis, Denmark

appeared in the Journal of Radioanalytical and Nuclear Chemistry, 215, No. 2 (1997) 157-160.

The correct statistical term "weighting" was consistently replaced during the editing process by the misleading term "weighing". 